\title{
Where's the patient's voice in health professional education?
}

In November 2015 the second international conference, 'Where's the Patient's Voice in Health Professional Education?' was held in Vancouver, Canada. The conference brought together 250 participants from 16 countries, including Brazil, to share experiences of involving patients as active participants in the education of health professionals. Uniquely for an academic conference, just over $20 \%$ of participants identified themselves as patients or community members and $13 \%$ were students. The conference was held 10 years after the first international conference on the topic in Vancouver which brought together the pioneers in the field to 'map the territory' of patient involvement'. In 2015 we learned about the significant progress that has been made over the past decade.

\section{Historical perspective on patient involvement}

The 'patient as teacher' has a long history. At the beginning of the $20^{\text {th }}$ century William Osler, one of the founding fathers of medical education, insisted that students learn from seeing and listening to patients. In Osler's model of education, students would learn medicine in the lecture hall and laboratory for the first two years, followed by two years in which the hospital would become the college, and the patient the centre of learning, with books and lectures as tools. Osler's idea of learning from the patient in the clinical setting continues to this day. Although the traditional 'bedside teaching' model is being replaced with more teaching in outpatient clinics or primary care, the patient's role is still essentially passive. The patient is used as a living textbook or 'clinical material' to illustrate some important or interesting aspect of disease or disability, or as a subject on which students can practice their clinical skills. In these traditional approaches, students learn 'on' and 'about' patients. More recently, however, patients have started to play much more active roles as educators by which students learn 'with' and 'from' them.

Programs that involve patients as teachers of core professional skills date back to the early 1970s and were developed as a response by professional educators to perceived problems with the teaching of clinical skills by clinicians, notably that students were rarely observed or given feedback on their performance ${ }^{2}$. Trained patient instructors who used their own bodies to teach and evaluate physical examination skills were able to give more time for practice and feedback than could busy clinicians. They also provided a safe learning environment in which students felt less pressure to 'perform' than when instructed by a clinician. One of the most long-lasting examples are arthritis patient educators who teach the musculo-skeletal examination. In addition patient instructors proved to be an ethical and realistic way to teach intimate examinations such as pelvic and breast examinations. Many of these programs have become embedded into the formal curricula of health professional programs.

Programs that involve patients in roles other than teachers of clinical skills first appeared in the early 1990s as part of a movement for active patient involvement created by the convergence of trends in health care delivery, policy and research that emphasized the active participation of the community and individual patients in many aspects of their care ${ }^{2}$, and the World Health Organization's call for medical schools to be socially accountable and address the priority health concerns of the communities they serve. The extension of policy directions for patient and public participation in the delivery of services into the education of the health and social care professionals who provide those 
services has been most notable in the UK, where government policies to develop a 'patient-led' National Health Service has resulted in the most wide ranging and institutionally supported 'patient as educator' initiatives in the world. Irrespective of national government policy, however, almost all health professions embrace a version of patient-centred care in their particular good practice model, which includes a focus on individual people's preferences, life circumstances and experience of illness.

\section{Benefits of learning from patients}

Patient involvement has now extended throughout the educational continuum (into postgraduate and continuing professional development) and across different health professions, including medicine, nursing, allied health professions and the training of interprofessional and multiprofessional teams.

Professional educators have discovered that the expertise of patients can enrich the education of students in a variety of ways, providing learning experiences that could not otherwise occur and broadening out curricula from the traditional biomedical model. The lived experience of disease (chronic illness or disability) is unique experiential knowledge not possessed by health professional educators. Students contrast 'dry book learning' with 'powerful', 'memorable', 'inspirational' learning from patients. Learning with patients helps students put their academic learning in context and promotes patient-centredness ${ }^{3}$. An aim of some patient involvement initiatives is to shape learners' attitudes and values. For example, Health Mentors programs, in which students interact with people from marginalized populations, are designed to overcome the stigma and stereotyping associated with certain groups such as the elderly, or people with mental illness or disabilities ${ }^{2}$. There is some evidence that these encounters do encourage more positive attitudes among students towards groups that receive poorer care or are underserved by health professionals. In summary, learning from patients can play a role in the development of clinical reasoning, communication skills, professional attitudes, empathic understanding and an individualized approach to the patient; it also motivates students by providing relevance and context ${ }^{2}$. There are also benefits to the patients involved in education, including satisfaction in giving back to the community, having an influence on the education of future professionals, and increased self-esteem and empowerment. However, there are few good quality outcomes studies, and there is a lack of evidence of the long-term impact on practice and benefits to the recipients of care.

\section{The spectrum of involvement}

The nature, duration, and even purpose, of active patient involvement in education are enormously variable from program to program and country to country. The ways in which patients can be involved in the education of health professionals can be considered along a spectrum of involvement ${ }^{2}$. At level 1 patients' stories are used to create learning materials that are used by professional educators and clinical teachers. For example patients' experiences can be used as the basis for case-based learning, virtual patients or scenarios for assessments. It is also now common practice that simulated and standardized patients are involved in the teaching and assessment of communication, history taking or physical examination skills (level 2). Patients are increasingly invited into the classroom to share their unique personal experience of illness and disability and of the health care system, or students may make family and community visits 
(level 3). At level 4 patients are actively engaged in a teaching role, either on their own or as co-teachers with professionals. They may undergo training for this enhanced role and become proficient in giving feedback to learners; patients may also assess students' competence in areas such as patient-centredness or communication. At level 5, patients are equal partners, not only on teaching but in curriculum development. They have membership on committees that is not tokenistic and are listened to and respected as educators and experts. Finally, patients are involved at institutional level in educational decision-making, for example about curriculum, student selection, faculty recruitment or program evaluation (level 6). However, examples of involvement at levels 5 and 6 are rare. Barriers to patient involvement in education include lack of institutional support and funding, challenges to professional knowledge and power, and issues of representativeness and tokenism.

\section{Future directions}

At the 'Where's the Patient's Voice in Health Professional Education?' conference we recognized that much progress has been made over the past decade. In many countries and professions there are innovative and high quality educational initiatives involving patients as educators. Patients themselves are increasingly confident that they have important contributions to make to education. However, we also found that many of these activities are driven by a small group of enthusiastic people working in isolation. Activities are often fragmented rather than being embedded into the educational structures of the institution, and they are often of low priority or status in the institution. To make further progress, conference participants generated a statement to set the agenda for the next five years ${ }^{4}$.

The conference statement summarizes the current state and highlights nine priorities for action over the next five years that are necessary in order to embed patient involvement in the education of health and social care professionals. They are in the areas of policy, recognition and support, innovation, research and evaluation, and dissemination and knowledge exchange. Of these, the actions that are most likely to bring about substantive change are those related to policy. Change at this level requires leadership from decision-makers in the health care system and professional bodies, as well as those directly responsible for the education of health and social care professionals. We call on all leaders, educators and clinicians to model and set expectations of collaboration and partnerships with patients early and often across the continuum of education in order to improve the quality of patient-centred care and health outcomes.

Angela Towle

Patient \& Community Partnership for Education, Office of the Vice-Provost Health, and Associate Professor, Department of Medicine, University of British Columbia,

Vancouver, Canada. angela.towle@ubc.ca 


\section{References}

1. Farrell C, Towle A, Godolphin W. Where's the patient's voice in health professional education? [Internet] [cited 2016 Feb 7]. Vancouver: Division of Health Care Communication, University of British Columbia; 2006. Available from: www.dhcc.chd. ubc.ca/sites/default/files/documents/PtsVoiceReportbook.pdf

2. Towle A, Bainbridge L, Godolphin W, Katz A, Kline C, Lown B, et al. Active patient involvement in the education of health professionals. Med Educ. 2010; 44(1):64-74.

3. Towle A, Godolphin W. Patients as educators: interprofessional learning for patientcentred care. Med Teacher. 2013; 35(3):219-25.

4. Towle A, Farrell C, Gaines ME, Godolphin W, John G, Kline C, et al. The patient's voice in health and social care professional education: the Vancouver Statement. Int J Health Gov. 2016 [in press]. 